\title{
ВЫДЕЛЕНИЕ КОНЦЕНТРАТА ЛАНТАНА И ЦЕРИЯ ИЗ ОТРАБОТАННОГО КАТАЛИЗАТОРА КРЕКИНГА ФТОРИДНЫМ СПОСОБОМ
}

\author{
Лосева ${ }^{I}$ E.A., Остапенко ${ }^{I}$ E.O. \\ ІОмский государственный технический университет, Омск, Россия
}

\begin{abstract}
Аннотация. В работе рассматриваются факторы, влиющие на максимальное выделение концентрата лантана и церия из отработанного катализатора крекинга по фторидной технологии. Их содержание в отработанном катализаторе крекинга сопоставимо в содержанием в промышленно перерабатываемых рудах. Используются в качестве вскрывающих агентов серной кислоты и фторида аммония. Использованы такие методы, как ИК-спектроскопия, рентгенофлуоресцентный анализ, сканирующая электронная микроскопия. В результате получен концентрат лантаноидов, которые содержатся в виде фторидов. Концентрация лантаноидов возрастает в несколько раз.

Abstract. The article discusses the factors influencing the maximum release of lanthanum and cerium concentrate from a spent cracking catalyst using fluoride technology. Their content in the spent cracking catalyst is comparable to the content in industrially processed ores. They are used as the opening agents of sulfuric acid and ammonium fluoride. Methods such as IR spectroscopy, X-ray fluorescence analysis, scanning electron microscopy were used. As a result, a concentrate of lanthanides was obtained, which are contained in the form of fluorides. The concentration of lanthanides increases several times.
\end{abstract}

Ключевые слова: редкоземельные металлы; отработанный катализатор крекинга; фториды

Keywords: rare earth metals; spent cracking catalyst; fluorides

\section{І. ВВЕДЕНИЕ}

Редкоземельные элементы (РЗЭ) используют в высокотехнологичных отраслях промышленности. В отработанном катализаторе крекинга (ОКК), марки «Авангард», производимого на Омском НПЗ, суммарно содержится $\sim 1 \%$ оксидов $\mathrm{La}$ и $\mathrm{Ce}$ (табл.1), что сопоставимо с их содержанием в промышленно перерабатываемых рудах. Однако в настоящее время ОКК не перерабатывают, а отправляют на полигоны для захоронения, что приносит непоправимый ущерб экологии.

СОСТАВ КАТАЛИЗАТОРА КРЕКИНГА НЕФТИ «АВАНГАРД»

Таблица 1

\begin{tabular}{|c|c|c|c|c|c|c|c|}
\hline о & $\mathrm{La} 2 \mathrm{O} 3$ & $\mathrm{Ce}_{2} \mathrm{O}_{3}$ & $\mathrm{Al}_{2} \mathrm{O}_{3}$ & $\mathrm{Fe}_{2} \mathrm{O}_{3}$ & $\mathrm{CaO}$ & $\mathrm{MgO}$ & $\mathrm{SiO}_{2}$ \\
\hline $\begin{array}{c}\text { Массовая доля, } \\
\%\end{array}$ & 0,67 & 0,08 & 26,4 & 0,64 & 7,84 & 2,58 & Остальное \\
\hline
\end{tabular}

Цель: выбрать рациональный способ переработки отработанного ОКК в конечные продукты.

Задачи: 1) определить состав концентрата РЗЭ после вскрытия ОКК спеканием с $\mathrm{NH}_{4} \mathrm{~F}$ и дальнейшим выщелачиванием соединений кремния и алюминия водой (метод 1); 2) определить состав концентрата РЗЭ после вскрытия ОКК спеканием с $\mathrm{NH}_{4} \mathrm{~F}$, дальнейшей сублимацией $\left(\mathrm{NH}_{4}\right)_{2} \mathrm{SiF}_{6}$ и выщелачиванием из остатка после сублимации соединений алюминия водой (метод 2); 3) определить состав концентрата РЗЭ после вскрытия ОКК смесью $\mathrm{H}_{2} \mathrm{SO}_{4}$ и $\mathrm{NH}_{4} \mathrm{~F}$ и дальнейшим выщелачиванием соединений кремния и алюминия водой (метод 3); 4) охарактеризовать полученные концентраты методами ИК-спектроскопии и рентгенофазового анализа (РФА).

II. КРАТКОЕ ОПИСАНИЕ УСЛОВИЙ ЭКСПЕРИМЕНТОВ

Содержание РЗЭ в остатке после сублимации и концентрате РЗЭ определяли методом атомноабсорбционной спектрометрии на приборе AA-6300 (Shimadzu) в режиме эмиссии, тип пламени — воздухацетилен.

Фазовый состав полученных осадков определяли методом порошковой рентгеновской дифракции с использованием дифрактометра ДРОН 3 в монохроматизированном $\mathrm{Cu}-\mathrm{K} \alpha$-излучении, в режиме измерения: шаг сканирования $-0,050$, время накопления -5 с/точка.

ИК-спектроскопия была проведена на приборе SpectrumOneFT-IR фирмы Perkin-Elmer (США). Образцы прессовали с бромидом калия в таблетки диаметром 7 мм и снимали спектры в диапазоне волновых чисел 4000 $400 \mathrm{~cm}^{-1}$.

III. РЕЗУЛЬТАТЫ ЭКСПЕРИМЕНТОВ

В данной работе рассмотрена методика выделения лантаноидов из ОКК с использованием в качестве вскрывающих агентов серной кислоты и фторида аммония. В результате взаимодействия диоксид кремния 
должен количественно удаляться из ОКК, а оксид алюминия - превращаться в легко растворимый сульфат. Соединения лантана, церия и магния переходят в нерастворимые фториды. Для эксперимента была взята навеска ОКК массой 0.5 г. На начальном этапе навеска ОКК смешивалась с компонентами согласно плану эксперимента. Получившийся осадок фильтровался, высушивался до постоянной массы и озолялся в муфельной печи. Наибольшая масса получившегося продукта -0.1391 г, наименьшая

-0.0075 г.

На рис. 1 показаны ИК спектры концентратов РЗЭ, полученных по 3 методикам.

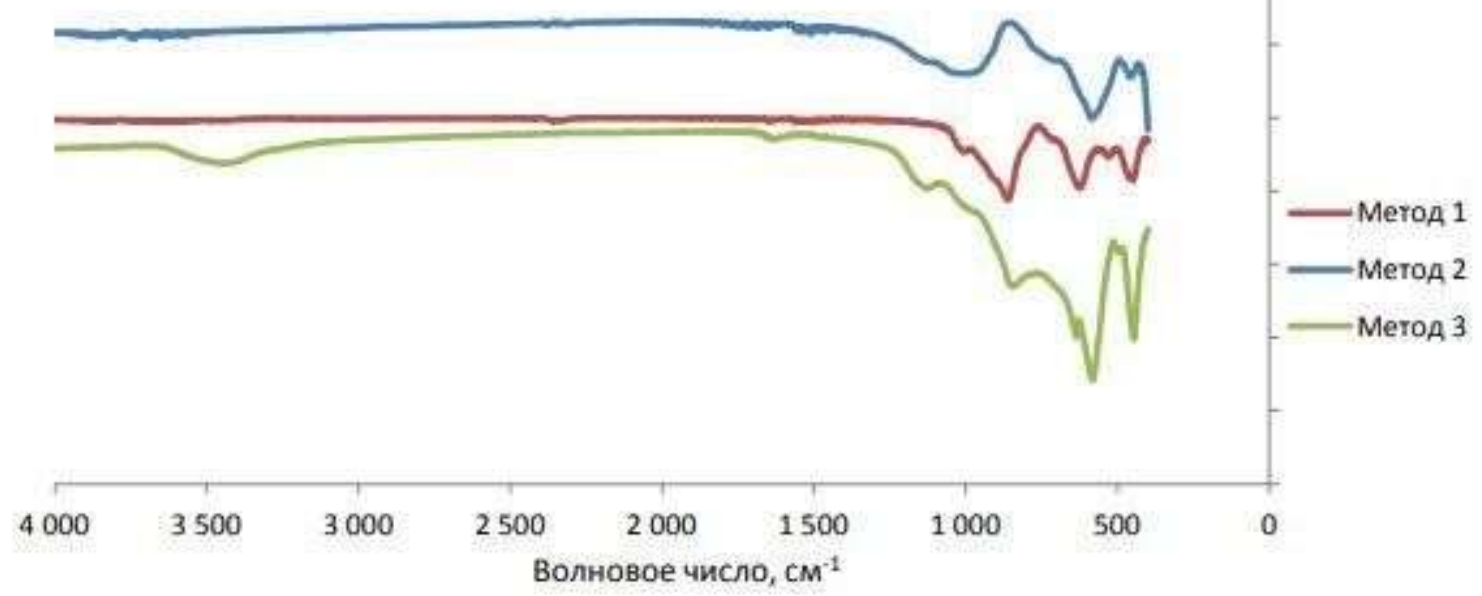

Рис. 1 ИК спектры концентратов РЗЭ: метод 1 - после фторирования и водного выщелачивания, метод 2 после фторирования, сублимации

(NH4)2SiF6 и водного выщелачивания, метод 3 - после взаимодействия

ОКК со смесью Н2SO4 и NH4F и водного выщелачивания

\section{IV. ОБСУЖДЕНИЕ РЕЗУЛЬТАТОВ}

После обработки результатов по методу наименьших квадратов была получена математическая зависимость, согласно которой на остаточную массу (а соответственно и на степень концентрирования лантаноидов) в большей степени влияют объём $\mathrm{H}_{2} \mathrm{SO}_{4}$ и длительность обработки, в меньшей степени температура обработки и масса $\mathrm{NH}_{4} \mathrm{~F}$.

Методом химического анализа было определено, что концентрация лантаноидов в концентрате возросла в 5-10 раз, алюминий и кремний остались в количестве $25-30 \%$ и 30-40\% соответственно (рис.1, рис.2). Остаточное содержание фтора в концентрате 5-6 \%. Методами ИКспектроскопии и РФА было определено, что основными фазами, присутствующими в концентрате, были топаз $\mathrm{Al}_{2} \mathrm{~F}_{2} \mathrm{SiO}_{4}$ и диоксид кремния $\mathrm{SiO}_{2}$, также были выявлены фториды лантана и церия.

На рис.2 показаны СЭМ микрофотографии концентратов РЗЭ, полученных по 3 методике.
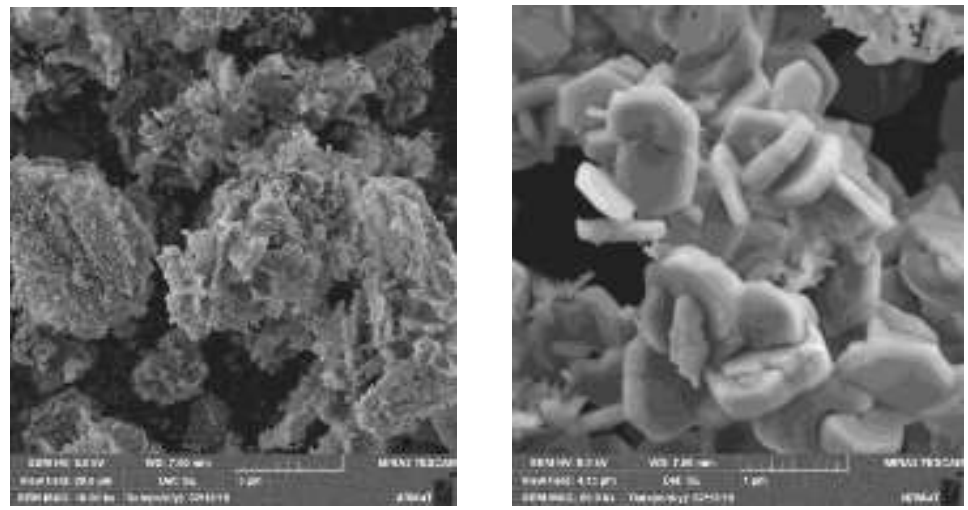

Рис.2 СЭМ концентратов РЗЭ, полученных по 3 методике а) образеи с наибольшей потерей массы при 10000 кратном увеличении б) образеи с наименьшей потерей массы при 50000 кратном увеличении 
На рис.3 показан РФА концентрата РЗЭ, полученного по 3 методике.

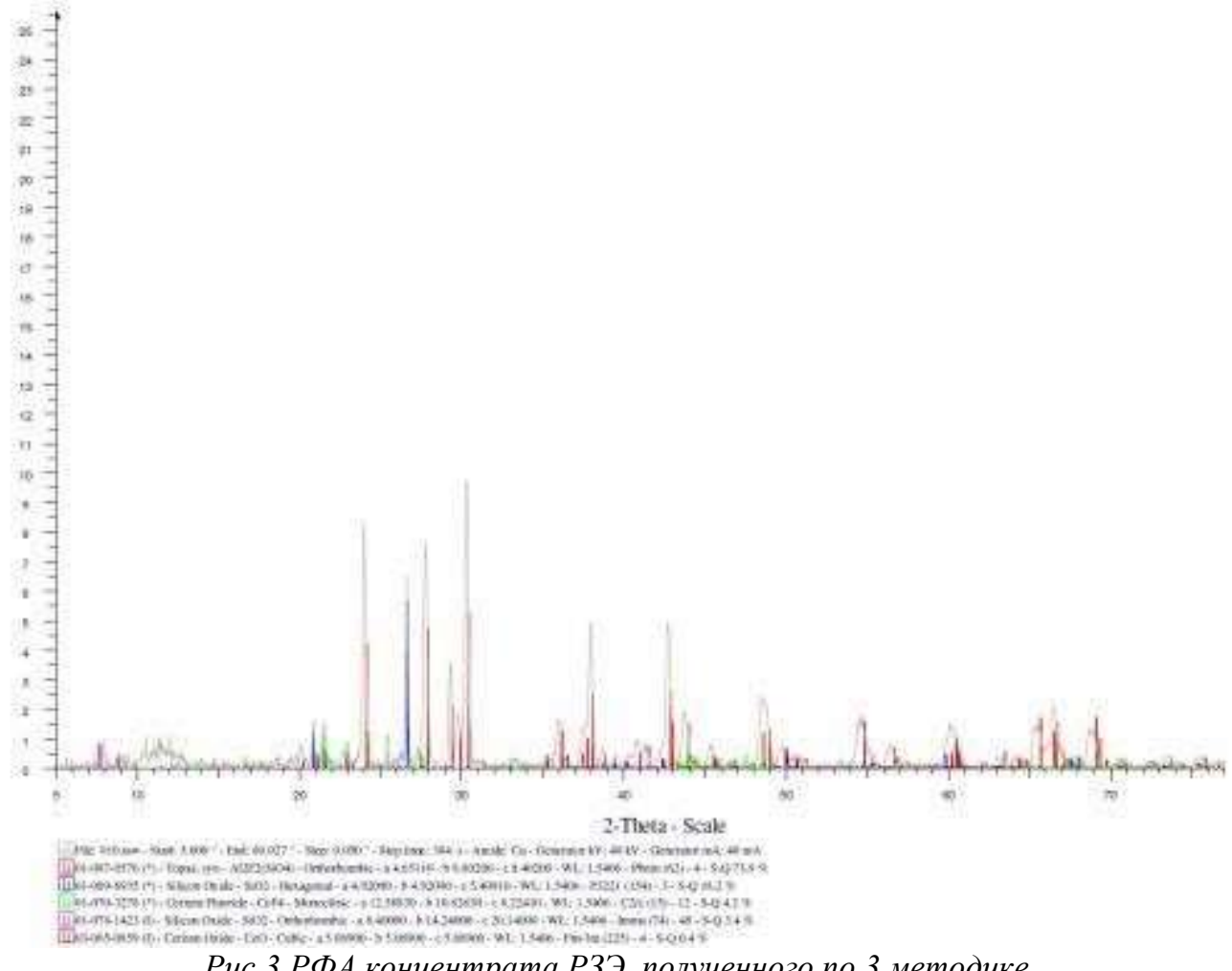

Рис.3 РФА концентрата РЗЭ, полученного по 3 методике

\section{V. ВЫВОДЫ И ЗАКЛЮЧЕНИЕ}

Таким образом, можно сделать вывод, что содержание лантаноидов в концентрате возрастает в 5-10 раз, они присутствуют в виде фторидов. На степень концентрирования лантаноидов в большей степени влияют объём $\mathrm{H}_{2} \mathrm{SO}_{4}$ и длительность обработки, в меньшей степени - температура обработки и масса $\mathrm{NH}_{4} \mathrm{~F}$.

\section{СПИСОК ЛИТЕРАТУРЫ}

1. Андреев М.Н. Анализ современного состояния добычи и обогащения редкоземельных металлов в России // Записки Горного института. 2014. Т.

207. C. 9-11.

2. Юшина Т.И., Петров И.М., Гришаев С.И., Черный С.А. Обзор рынка РЗМ и технологий переработки редкоземельного сырья // Горный информационно-аналитический бюллетень. 2015. С. 577-608.

3. Khludnev A. M., Kovtunenko V. A. Analysis of cracks in solids.

4. Southampton // Eur. J. 2017. Vol. 2. Pp. 1-3. 